\title{
Treatment with Biologicals in Rheumatoid Arthritis: An Overview
}

Philipp Rein (1) - Ruediger B. Mueller

Received: May 22, 2017 / Published online: August 22, 2017

(C) The Author(s) 2017. This article is an open access publication

\begin{abstract}
Management and therapy of rheumatoid arthritis (RA) has been revolutionized by the development and approval of the first biological disease-modifying antirheumatic drugs (bDMARDs) targeting tumor necrosis factor (TNF) $\alpha$ at the end of the last century. Today, numerous efficacious agents with different modes of action are available and achievement of clinical remission or, at least, low disease activity is the target of therapy. Early therapeutic interventions aiming at a defined goal of therapy (treat to target) are supposed to halt inflammation, improving symptoms and signs, and preserving structural integrity of the joints in RA. Up to now, bDMARDs approved for therapy in RA include agents with five different modes of action: TNF inhibition, $\mathrm{T}$ cell co-stimulation blockade, IL-6 receptor
\end{abstract}

CME content This article has associated CME accreditation, valid until August 2018. Please follow this link to access the activity: https://rheumatology. medicinematters.com/mmr1703/14216360.

Enhanced content To view enhanced content for this article go to http://www.medengine.com/Redeem/ 59F8F060212D2A95.

P. Rein $(\varangle) \cdot$ R. B. Mueller

Division of Rheumatology, Immunology and

Rehabilitation, Kantonsspital St. Gallen, St. Gallen,

Switzerland

e-mail: philipp.rein@kssg.ch inhibition, B cell depletion, and interleukin 1 inhibition. Furthermore, targeted synthetic DMARDs (tsDMARDs) inhibiting Janus kinase (JAK) and biosimilars also are approved for RA. The present review focuses on bDMARDs and tsDMARDS regarding similarities and possible drug-specific advantages in the treatment of RA. Furthermore, compounds not yet approved in RA and biosimilars are discussed. Following the American College of Rheumatology (ACR) and European League Against Rheumatism (EULAR) recommendations, specific treatment of the disease will be discussed with respect to safety and efficacy. In particular, we discuss the question of favoring specific bDMARDs or tsDMARDs in the two settings of insufficient response to methotrexate and to the first bDMARD, respectively.

Keywords: B cell depletion; Biological DMARDs; IL-6 receptor inhibition; Janus kinase inhibitors; Review; Rheumatoid arthritis; $\mathrm{T}$ cell co-stimulation blockade; Targeted synthetic DMARDs; Therapy; TNF inhibitors

\section{INTRODUCTION}

Rheumatoid Arthritis (RA) is a chronic inflammatory systemic disease affecting approximately $1 \%$ of the population with a higher frequency in 
women than in men [1]. Inflammation in RA primarily affects the small joints and is characterized by pain and swelling, thereby leading to chronic progressive joint destruction causing a decline in quality of life, physical function, and working ability. Cytokines such as tumor necrosis factor $\alpha$ (TNF) and interleukin 6 (IL-6) play a specific role in the inflammatory processes in RA [2]. As inflammation drives symptoms (pain and swelling of joints) and sequentially damage (loss of function leading to work disability), suppression of inflammation is the main target in RA. As a result of its systemic nature, the individual burden of the disease is not necessarily limited to the joints but also results from fatigue, depression, osteoporosis, and an increased risk for cardiovascular disease [3].

Management of RA has dramatically improved in the last few decades: In former times, the disease was diagnosed late and relief of symptoms or prevention of adverse events was the main goal of therapy. For much of the last century, available compounds for therapy in RA had limited efficacy but significant toxicity. Management and therapy of RA has been revolutionized by the development and approval of the first biological disease-modifying antirheumatic drugs (bDMARDs) targeting TNF at the end of the last century. Today, numerous efficacious agents with different modes of action are available and achievement of clinical remission or, at least, low disease activity is the target of therapy. Earlier treatment in the course of RA leads to a higher clinical efficacy [4] and, consequently, the 2010 American College of Rheumatology/ European League Against Rheumatism (ACR/ EULAR) classification criteria focus on enabling diagnosis of RA in early stages of the disease [5]. Within this phase of the disease, active inflammation instead of irretrievable structural damage is the key driver of symptoms and disability. Early therapeutic interventions aiming at a defined goal of therapy (treat to target) are supposed to halt inflammation, improving symptoms and signs, and preserving structural integrity of the joints in RA [6].

Up to now, biological DMARDs approved for therapy in RA include agents with five different modes of action: TNF inhibition, T cell co-stimulation blockade, IL-6 receptor inhibition, B cell depletion, and interleukin 1 inhibition. Furthermore, targeted synthetic DMARDs (tsDMARDs) inhibiting Janus kinase (JAK) and biosimilars also are approved for RA. Currently, five TNF inhibitors (adalimumab, certolizumab pegol, etanercept, golimumab, and infliximab) and two tsDMARDs inhibiting JAK (tofacitinib and baricitinib) are approved for therapy in RA. The present review focuses on bDMARDs and tsDMARDs regarding similarities and possible drug-specific advantages in the treatment of RA. Furthermore, compounds not yet approved in RA and biosimilars are discussed. Following the ACR and EULAR recommendations, specific treatment of the disease will be discussed with respect to the first biologic intervention and management after failure of the first bDMARD, respectively. This article is based on previous studies and does not involve any new studies on human or animal subjects performed by the authors.

\section{MANAGEMENT OF MTX INSUFFICIENT RESPONDERS}

\section{Efficacy of Approved Biological DMARDs}

According to the recently updated EULAR recommendations on RA [7], therapy with conventional synthetic DMARDs (csDMARDs) should be started immediately after having diagnosed RA and methotrexate (MTX) should be part of the first treatment strategy. Using MTX, however, a large proportion of patients do not achieve remission or low disease activity $[8,9]$. In general, bDMARDs or tsDMARDs should be considered if the first csDMARD does not achieve treatment target in the presence of negative prognostic factors or if response to two csDMARDs is insufficient in the absence of negative prognostic factors.

In the setting of MTX-IR (MTX incomplete responders), neither the EULAR nor the ACR recommendations favor the use of one specific bDMARD or tsDMARD or suggest a certain sequence of its use $[7,10]$ : This strategy of recommending all agents without hierarchical positioning is a novelty compared to the 2013 version of the EULAR recommendations [11] and is well in line with the published evidence 


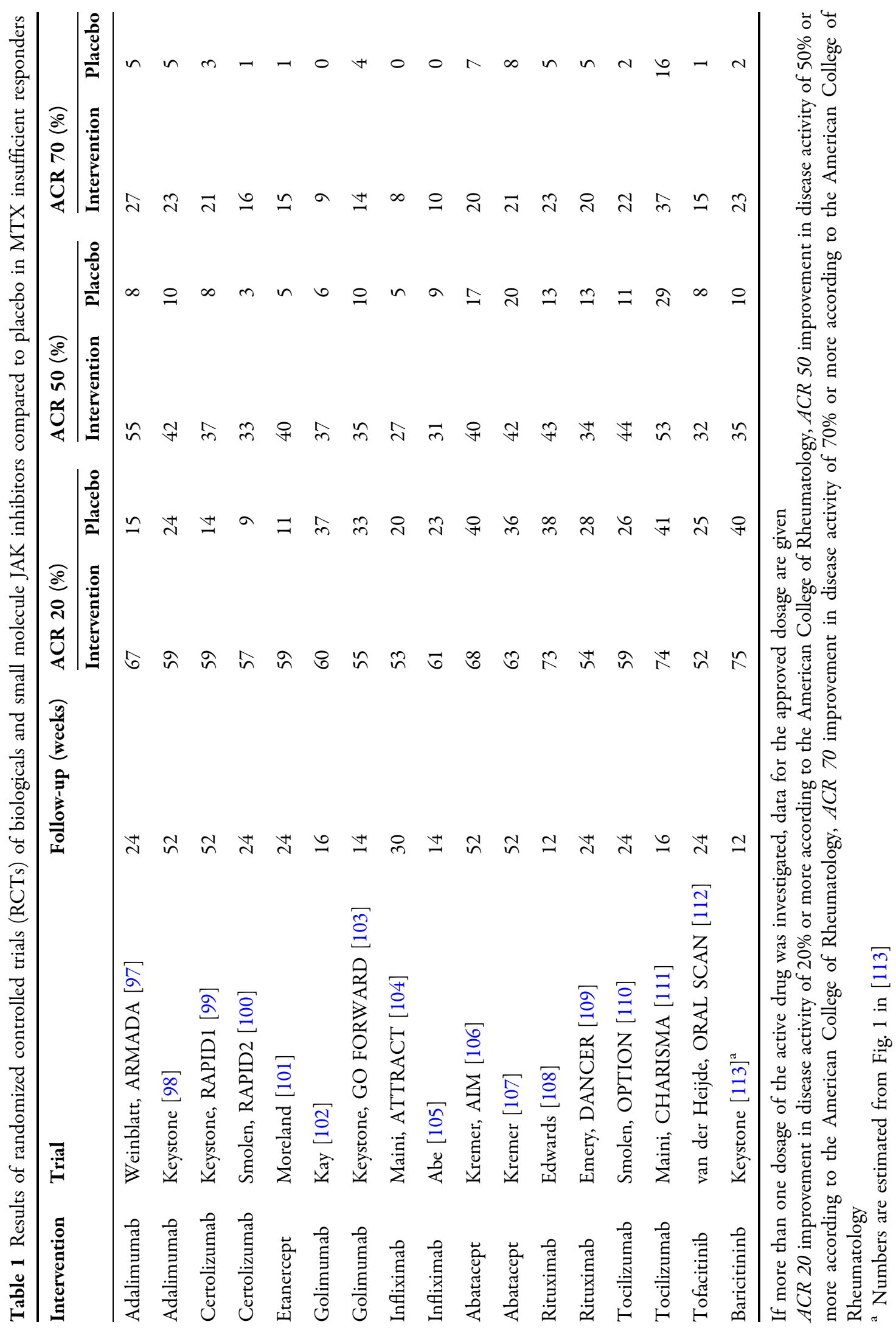


(Table 1): First, head-to-head studies in MTX-IR directly comparing bDMARDs with different modes of action in combination with MTX are scarce. The Ample study investigated the clinical efficacy of abatacept versus adalimumab in an MTX-IR RA cohort. Clinical efficacy (ACR 20 response rate $64.8 \%$ in the abatacept and $63.4 \%$ in the adalimumab groups) and inhibition of radiographic progression were similar within these two agents [12]. Tofacitinib was as effective as adalimumab in a randomized study (ACR 20 response rates $51.5 \%, 52.6 \%$, and $47.2 \%$ among patients receiving 5 or $10 \mathrm{mg}$ of tofacitinib or those receiving adalimumab) [13]. Second, studies directly comparing TNF inhibitors are still lacking with the exception of the EXXELARATE trial investigating adalimumab and certolizumab pegol in MTX-IR. Results proved that the efficacy of certolizumab pegol was not significantly different to that of adalimumab, both in combination with MTX (ACR 20 response rates $65 \%$ for certolizumab pegol and $67 \%$ for adalimumab) [14]. Third, indirect comparisons strongly point to a similar efficacy within all bDMARDs when used in combination with MTX [15].

In general, bDMARDs are used in combination with MTX. However, more than one-third of patients are intolerant to MTX [16] and adherence is often poor, especially when administered orally [17]. Consequently, about $30 \%$ of patients in clinical practice are treated with bDMARDs in monotherapy [18]. Next to MTX, various csDMARDs have been analyzed for their efficacy in RA patients. However, the combination of these other csDMARDs with bDMARDs has not been tested extensively: In the REACT [19] and the oral Sync studies [20], the combination of adalimumab or tofacitinib, respectively, with different csDMARDs including sulfasalazine, leflunomide, antimalarials, azathioprine, and gold demonstrated proven efficacy. Furthermore, the combination of TNF inhibitors with leflunomide was as effective and equally well tolerated as TNF inhibitors plus MTX [21]. Similarly, disease activity and functional disability did not differ significantly between tocilizumab plus MTX versus tocilizumab plus leflunomide [22].

Special focus has to be given to the clinically relevant issue of using bDMARDs or tsDMARDs in monotherapy: Tocilizumab was the first biological agent to show statistically significant clinical efficacy superior to MTX when used in monotherapy, although approximately twothirds of patients in the MTX group reached and maintained a $20 \mathrm{mg}$ MTX/week dose by week 8 [23]. The randomized controlled ADACTA trial evaluated adalimumab versus tocilizumab in RA patients with an insufficient response or intolerance to MTX-both agents were used in monotherapy. This superiority study showed a significantly greater clinical improvement with tocilizumab compared to adalimumab (ACR 20 response rates $65.0 \%$ vs. $49.4 \%$ ) [24]. In an open-label study, tocilizumab was similarly effective, when used as monotherapy or in combination with csDMARDs [25]. The ACT-RAY was a double-blind study to compare adding tocilizumab versus switching to tocilizumab monotherapy in MTX-IR. In this study, no clinically relevant superiority of the addition of tocilizumab to MTX over the switch to tocilizumab monotherapy was proven, but there was a modest difference in the percentage of patients with DAS28 remission and in the inhibition of radiographic progression favoring the addition strategy [26, 27]. Adding tocilizumab to MTX in patients with active disease despite MTX was clinically and radiographically superior compared to switching from MTX to tocilizumab in another two randomized trials [28, 29]. Regarding monotherapy with tsDMARDs, ACR 20 response rates were similar for baricitinib plus placebo compared to baricitinib plus MTX (nearly 80\% in both groups) in a recently published RCT [30], and the effect of tofacitinib was irrespective of the dosage of background MTX [31]. To sum up, the use of tocilizumab or of tsDMARDs is a reasonable evidence-proven strategy in case of monotherapy in RA, especially in patients who do not tolerate or cannot be treated with MTX.

\section{Safety Issues Regarding Approved Biological Compounds in RA}

Compared to csDMARDs, biological drugs in RA are associated with an increase in the number of serious infections of six per 1000 patients 
treated each year [32]. Increasing age, comorbidity, glucocorticoid use, and previous history of serious infections were significant predictors of future infections in different databases, including the German RABBIT register. The overall relative risk of treatment with TNF inhibitors compared with that of csDMARDs was 1.8 in the RABBIT cohort, meaning that the absolute risk increase depends on baseline risk in different groups of patients [33]. For daily practice, an online calculator has been developed [34]. The rates of serious infections in RCTs of newer biologicals appear to be in general consistent with rates seen in the anti-TNF registers of between two and six per 100 patient years of follow-up [35]. The ACR 2015 guideline for the treatment of RA has addressed the issue of safety [10]. Supported by low-level evidence, the ACR recommends to use csDMARDs in combination over TNF inhibitors in patients with previous serious infections and to use abatacept over TNF inhibitors within these high-risk patients, mainly driven by the results of the ATTEST trial, demonstrating less serious infections with a lower need of hospitalizations during therapy with abatacept compared to infliximab [36, 37]. These recommendations are conditional, meaning that the special recommendation is applicable to the majority of patients, but some may not want to follow the recommendation.

After approval of TNF inhibitors, reports of new onset or deterioration of heart failure were reported for infliximab dosed at $10 \mathrm{mg} / \mathrm{kg}$ [38]. This could not be reproduced with etanercept [39]. In parallel, a recent review shows that the rate of heart failure is not increased in patients receiving TNF inhibitors. Furthermore, risk of symptomatic congestive heart failure was not increased in the high risk group of patients with established heart failure during therapy with TNF inhibitors [40].

When initiating a biological DMARD, special focus relates to the increased risk of opportunistic infections [41] and to check for latent tuberculosis. Risk for reactivation of tuberculosis is higher in patients receiving anti-TNF monoclonal antibodies compared to etanercept. One reason therefore might be the importance of membrane-bound TNF in protecting against tuberculosis, which is neutralized by the TNF antibody but not by the TNF receptor fusion molecule $[42,43]$. In contrast, increased risk of reactivation was not seen during therapy with rituximab in RA. In mice, abatacept did not impair the ability to control a chronic Mycobacterium tuberculosis infection [44]. Tuberculosis (TB) was rarely seen during therapy with tofacitinib and it was speculated that some of the observed TB cases were instances of newly acquired infection during the trial, given that nearly all the cases occurred in regions of high TB endemicity where exposure would be more likely [45]. No increased risk for tuberculosis reactivation was seen with tocilizumab in RCTs [46]. In general, prior to treatment with all approved bDMARDs in MTX-IR, the wellknown screening algorithm should be applied [10].

With respect to vaccination, treatment with rituximab and with MTX in monotherapy is associated with impaired vaccine responses, and temporary MTX discontinuation improves the immunogenicity of seasonal influenza vaccination in patients with RA [47, 48]. In contrast, tofacitinib had less impact on vaccination responses [49], whereas TNF inhibitors and tocilizumab did not reduce vaccination response $[47,50]$.

A special safety issue during therapy with tocilizumab is the risk of lower intestinal perforation (LIP). Recently, real-life data from Europe found a significantly higher rate of LIP in tocilizumab-treated patients compared to patients treated with csDMARDs and other bDMARDs. Importantly, risk for LIP was not attenuated after adjustment for concomitant glucocorticoid use in Cox regression analysis [51]. In our opinion, a medical history positive for diverticulitis contradicts the use of tocilizumab, knowing that most cases with LIP did not have a history of diverticulitis. Patients should be informed about this risk and the fact that negative markers of inflammation cannot be interpreted during therapy with tocilizumab.

Regarding malignancies, cancer, lymphoma, melanoma, and non-melanoma skin cancer do not occur more frequently in patients on TNF inhibitors compared to patients on conventional DMARDs $[52,53]$. However, rituximab is 
the first choice in the case of certain comorbidities, e.g., concomitant multiple sclerosis or past or present lymphoproliferative disorders.

As $30-40 \%$ of RA patients show an inadequate response to bDMARDs, trials investigating the combination of two bDMARDs with different modes of action have been done. However, the combination of abatacept plus TNF inhibitors [54], of an interleukin-1 receptor antagonist plus TNF inhibitors [55], and of rituximab plus TNF inhibitors [56] demonstrated a lack of added benefit and at least the first two combinations significantly increased the rates of adverse events including serious infections.

\section{MANAGEMENT IN TNF INSUFFICIENT RESPONDERS (TNF-IR)}

There is still ambiguity how to manage RA patients with an inadequate response to the first TNF inhibitor. Keeping in mind the growing number of modes of action and consequently bDMARDs, this is a central question. Observational data indicate an advantage in changing the mode of action in TNF-IR $[57,58]$. The ACR consequently recommends the use of a non-TNF biological in case of an insufficient response to the first TNF inhibitor [10]. In primary non-responders to the first TNF inhibitor, data from one randomized trial and several observational studies point to less clinical response after switching to a second TNF inhibitor in primary TNF inhibitor non-responders compared to secondary non-responders or patients stopping the first TNF inhibitor because of adverse events [59-62]. Within primary non-responders, disease might be mediated by cytokines other than TNF, and consequently these patients could experience greater benefit from compounds using modes of action other than blocking TNF. In contrast, EULAR recommends to employ a second TNF inhibitor or an agent with a different mode of action without a hierarchical ranking, if one TNF inhibitor has failed [7]. Randomized controlled head-to-head studies once more are scarce, with the exception of the EXXELARATE study corroborating this recommendation: About $60 \%$ of patients switching to a second TNF inhibitor after primary failure to the first TNF inhibitor achieved a DAS28 reduction of at least 1.2 points [14]. Recommendation differs in patients failing TNF inhibition in monotherapy: As stated above, the use of tocilizumab or tsDMARDs is our recommended strategy in TNF-IR on monotherapy with bDMARDs.

Patients with secondary inefficacy to TNF inhibitors may have lost response because of the development of antidrug antibodies; these patients would therefore be expected to exhibit a clinically relevant response to an antigenically distinct treatment. Data from a randomized placebo-controlled trial demonstrated efficacy and safety of certolizumab in RA patients with secondary inadequate response or intolerance to the previous TNF inhibitors [63]. Importantly, patients developing antibodies to a first TNF inhibitor are at higher risk for developing antibodies to a subsequently employed TNF inhibitor. Therefore, immunogenicity might be the cause leading to the lower clinical efficacy of the second TNF inhibitor observed in TNF-IR $[57,64]$. Within this context, changing the mode of action in patients failing treatment with TNF inhibitors is worth considering, especially as abatacept [65], golimumab [61], rituximab [66-68], tocilizumab [69, 70], tofacitinib [71], and baricitinib [72] demonstrated clinical efficacy in patients with a previously inadequate response to at least one TNF inhibitor (Table 2). However, direct head-to-head comparisons using compounds with different modes of action in TNF-IR are still lacking. Moreover, we still do not have any data exploring the efficacy and safety of TNF inhibitors used after non-TNF-inhibiting bDMARDs have failed, of a second IL- 6 receptor inhibitor after tocilizumab has failed, and of a second JAK inhibitor after the first has failed. In summary, selection of the next bDMARD in TNF-IR is still undetermined, whereas EULAR and ACR both recommend switching to a non-TNF biological if a second TNF inhibitor fails.

Despite observational data and indirect comparisons pointing to a lower risk of infection during treatment with rituximab [73, 74], there was no consensus for making recommendations regarding the use of the CD20 
Table 2 Results of randomized controlled trials of biologicals and small molecule JAK inhibitors compared to placebo in TNF insufficient responders

\begin{tabular}{|c|c|c|c|c|c|c|c|c|}
\hline \multirow[t]{2}{*}{ Intervention } & \multirow[t]{2}{*}{ Trial } & \multirow{2}{*}{$\begin{array}{l}\text { Follow-up } \\
\text { (weeks) }\end{array}$} & \multicolumn{2}{|l|}{ ACR $20(\%)$} & \multicolumn{2}{|l|}{ ACR $50(\%)$} & \multicolumn{2}{|l|}{ ACR $70(\%)$} \\
\hline & & & Intervention & Placebo & Intervention & Placebo & Intervention & Placebo \\
\hline Golimumab & $\begin{array}{l}\text { Smolen, GO } \\
\text { AFTER [61] }\end{array}$ & 24 & 35 & 17 & 16 & 5 & 10 & 3 \\
\hline Abatacept & $\begin{array}{l}\text { Genovese, } \\
\text { ATTAIN [65] }\end{array}$ & 24 & 50 & 20 & 20 & 4 & 10 & 2 \\
\hline Rituximab & $\begin{array}{l}\text { Cohen, REFLEX } \\
\text { [66] }\end{array}$ & 24 & 51 & 18 & 27 & 5 & 12 & 1 \\
\hline Rituximab & $\begin{array}{l}\text { Emery, SERENE } \\
{[67]}\end{array}$ & 24 & 51 & 23 & 26 & 9 & 9 & 10 \\
\hline Tocilizumab & $\begin{array}{l}\text { Emery, RADIATE } \\
{[70]^{\mathrm{a}}}\end{array}$ & 24 & 50 & 10 & 29 & 4 & 12 & 1 \\
\hline Tofacitinib & $\begin{array}{l}\text { Burmester, ORAL } \\
\text { Step [71] }\end{array}$ & 12 & 42 & 24 & 27 & 8 & 14 & 2 \\
\hline Baricitinib & $\begin{array}{l}\text { Genovese, RA } \\
\text { BEACON [72] }\end{array}$ & 12 & 55 & 27 & NA & NA & NA & NA \\
\hline
\end{tabular}

If more than one dosage of the active drug was investigated, data for the approved dosage are given $A C R 20$ improvement in disease activity of $20 \%$ or more according to the American College of Rheumatology, $A C R 50$ improvement in disease activity of $50 \%$ or more according to the American College of Rheumatology, $A C R 70$ improvement in disease activity of $70 \%$ or more according to the American College of Rheumatology

${ }^{a}$ Data are given for rituximab $2 \times 1000 \mathrm{mg}$

antibody over TNF inhibitors in the setting of previous serious infections. A pooled analysis of safety data reported a rate of serious infections with rituximab that was comparable to that with MTX and reactivation of tuberculosis does not occur more frequently in RA treated with rituximab [75].

Furthermore, the frequency of serious infections was similar in TNF-IR randomized to abatacept compared to the placebo group $(10.5 \%$ and $11.3 \%$ ) [65]. In the few head-to-head trials, incidence of serious infections was not statistically significantly different between two TNF inhibitors (EXXELERATE, 2.2\% in certolizumab pegol vs. $2.0 \%$ in adalimumab treated patients) [14], and a TNF inhibitor compared to tocilizumab and baricitinib [24, 76], whereas abatacept had a more acceptable safety profile than infliximab as already mentioned [36]. In contrast, a recent meta-analysis suggests an increased risk of adverse events for certolizumab pegol during the first months of treatment [77].

In general, RCTs in TNF-IR ask for a washout phase of at least 4 weeks after the last injection or infusion of TNF inhibitors. However, the need for a washout phase has been rebutted in the ARRIVE, ACT-SURE, and EXXELARATE trials $[14,69,78]$. In our clinic, we have generally abandoned the use of a washout period. We directly start the new compound at the date scheduled for the next infusion or injection of the formerly used agent in TNF-IR. In our hands, no increase of adverse events was found (unpublished data).

\section{PRACTICABILITY}

In 2017, treating physicians have the possibility to choose not only among biological 
compounds with different modes of action but also with different routes of administration. Abatacept and tocilizumab are approved for use via subcutaneous injection or intravenous access. Head-to-head studies comparing the intravenous and subcutaneous route of administration of these two agents did not show any difference in clinical efficacy and safety, except that injection site reactions were more common with the subcutaneous access [24, 79]. Abatacept has demonstrated that switching from weekly subcutaneous to intravenous abatacept and back is effective and safe and may be used to bridge 4 weeks, e.g., to cover a vacation [80]. In real life, about $50 \%$ of patients with subcutaneous injections do not feel confident about injecting themselves [81]. Data investigating compliance with the orally administered JAK inhibitors are lacking. In our clinic, we observed a sinusoidal course in disease activity among patients treated with tofacitinib in real life, raising the issue of poor compliance. This might be the case especially in phases of good control of inflammation (manuscript under preparation).

\section{COMPOUNDS NOT YET APPROVED IN THE TREATMENT OF RA}

Sarilumab inhibits IL-6-mediated signalling by specifically binding to both soluble and membrane-bound IL- 6 receptors. Administered subcutaneously every 2 weeks, sarilumab significantly improved disease activity in MTX-IR and TNF-IR [82, 83]. Moreover, sarilumab was superior to adalimumab (both in monotherapy) by improving clinical disease activity in RA patients unable to continue MTX (ACR 20 response rates $71.1 \%$ in sarilumab-treated patients vs. $58.4 \%$ in adalimumab-treated patients) [84]. Similarly, HAQ-DI score and patient-reported outcomes improved at a statistically significant greater extent in the sarilumab group compared to the adalimumab group. The incidence of infections was similar between the two groups. Treatment with the IL-12/23 antibody ustekinumab and the IL-23 antibody guselkumab did not significantly reduce disease activity in rheumatoid arthritis patients with an inadequate response to MTX (ACR 20 response $53.6 \%$ and $41.3 \%$ vs. $40.0 \%$ in placebo) [85]. The data for the compounds secukinumab and brodalumab blocking the cytokines IL-17 and IL-23 in RA are far disappointing [86, 87], whereas ixekizumab improved RA signs and symptoms in patients naive to or with an inadequate response to TNF inhibitors [88]. It is therefore questionable if IL-17 and IL-23 blocking agents will be competitive against the already approved and available compounds in RA.

\section{BIOSIMILARS}

EULAR mentions that biosimilars approved by the European Medical Agency (EMA) or the US Food and Drug Administration (FDA) have similar efficacy and safety as the respective biological originator, and should be preferred if they are indeed appreciably cheaper than the originator or other biological compounds [7]. Biosimilar infliximab is already widely available, whereas biosimilar etanercept and biosimilar rituximab are approved merely by the FDA at the moment, but the EMA recommended approval recently [89]. Furthermore, a substantial pipeline of biosimilars is in development, including biosimilar adalimumab, which is recommended for approval [90].

\section{TAPERING AND WITHDRAWAL}

If a patient is in persistent remission after having tapered steroids, tapering bDMARDs can be considered [7]. Reducing from 50 to $25 \mathrm{mg}$ etanercept injected once per week or increasing the time interval between the etanercept or adalimumab injections was non-inferior to usual continued medication with respect to the preservation of clinical remission or low disease activity and the rate of clinically relevant flares [91, 92]. In contrast, abrupt cessation of bDMARD therapy led to flares in many if not most of the patients, not all of these regaining their former state of remission or low disease activity after restart of bDMARDs. In the ACT-Ray study, $50 \%$ of patients discontinued 
tocilizumab following sustained clinical remission after 1 year. Subsequently, $84 \%$ of these patients experienced a flare-up with recurrent response to the reintroduced drug [93]. In the CERTAIN double-blind randomized trial, patients who achieved remission during treatment with certolizumab pegol and csDMARD stopped treatment. Only three of the 17 prior certolizumab pegol patients maintained remission until week 52 [94]. In line with EULAR recommendations, in cases of persistent remission, tapering the csDMARD could be considered. However, this recommendation is a matter of debate, as many rheumatologists never would stop a csDMARD and leave patients without any disease-modifying therapy [7].

\section{CONCLUSIONS}

In general, important steps for controlling the progression of the disease have to be taken long before choosing a bDMARD: Early identification of RA represents the crucial step. Therefore we have to emphasize the importance of awareness for RA within the population and general practitioners. Perhaps even more challenging is the next step: Patients suspected of suffering from RA have to be seen by rheumatologists quickly, and if diagnosed, treatment with preferentially MTX should be started immediately. Initiating therapy within 3 months of disease onset played the most important role in achieving remission [95]. Even the worst prognostic factors lost significance when patients were treated aggressively and promptly in the BeST trial [96]. Treatment decisions have to be based on measures of disease activity and should be aimed at reaching remission or low disease activity, with respect to patient factors. Frequent follow-up visits especially in active disease and the overarching principle of treat-to-target are particularly important for successful therapy of RA. However, predictors for differential response to the different bDMARDs and tsDMARDs are missing. We still do not know which patient will best respond to which drug in which stage of disease and pretreatment. To provide better justification for the decision to prefer a specific
bDMARD in different situations, future randomized head-to-head studies are urgently required.

\section{ACKNOWLEDGEMENTS}

No funding or sponsorship was received for this study or publication of this article. All named authors meet the International Committee of Medical Journal Editors (ICMJE) criteria for authorship for this manuscript, take responsibility for the integrity of the work as a whole, and have given final approval for the version to be published.

Disclosures. Philipp Rein: Dr Rein has no relevant financial relationships to disclose.

Ruediger B Mueller: Consultant: AbbVie, UCB, Roche, BMS, Antares, Pfizer. Research grant: Roche, BMS, UCB.

Compliance with Ethics Guidelines. This article is based on previous studies and does not involve any new studies on human or animal subjects performed by the authors.

Open Access. This article is distributed under the terms of the Creative Commons Attribution-NonCommercial 4.0 International License (http://creativecommons.org/licenses/ by-nc/4.0/), which permits any noncommercial use, distribution, and reproduction in any medium, provided you give appropriate credit to the original author(s) and the source, provide a link to the Creative Commons license, and indicate if changes were made.

\section{REFERENCES}

1. Gabriel SE. The epidemiology of rheumatoid arthritis. Rheum Dis Clin North Am. 2001;27:269-81.

2. Furst DE, Emery P. Rheumatoid arthritis pathophysiology: update on emerging cytokine and cytokine-associated cell targets. Rheumatology (Oxford). 2014;53:1560-9. 
3. Kitas GD, Gabriel SE. Cardiovascular disease in rheumatoid arthritis: state of the art and future perspectives. Ann Rheum Dis. 2011;70:8-14.

4. Nell VP, Machold KP, Eberl G, Stamm TA, Uffmann $\mathrm{M}$, Smolen JS. Benefit of very early referral and very early therapy with disease-modifying anti-rheumatic drugs in patients with early rheumatoid arthritis. Rheumatology (Oxford). 2004;43:906-14.

5. Aletaha D, Neogi T, Silman AJ, et al. 2010 rheumatoid arthritis classification criteria: an American College of Rheumatology/European League Against Rheumatism collaborative initiative. Ann Rheum Dis. 2010;69:1580-8.

6. Gremese E, Salaffi F, Bosello SL, et al. Very early rheumatoid arthritis as a predictor of remission: a multicentre real life prospective study. Ann Rheum Dis. 2013;72:858-62.

7. Smolen JS, Landewe R, Bijlsma J, et al. EULAR recommendations for the management of rheumatoid arthritis with synthetic and biological disease-modifying antirheumatic drugs: 2016 update. Ann Rheum Dis. 2017;76:960-77.

8. Braun J, Kastner P, Flaxenberg P, et al. Comparison of the clinical efficacy and safety of subcutaneous versus oral administration of methotrexate in patients with active rheumatoid arthritis: results of a six-month, multicenter, randomized, double-blind, controlled, phase IV trial. Arthritis Rheum. 2008;58:73-81.

9. Muller RB, von Kempis J, Haile SR, Schiff MH. Effectiveness, tolerability, and safety of subcutaneous methotrexate in early rheumatoid arthritis: a retrospective analysis of real-world data from the St. Gallen cohort. Semin Arthritis Rheum. 2015;45:28-34.

10. Singh JA, Saag KG, Bridges SL Jr, et al. 2015 American College of Rheumatology guideline for the treatment of rheumatoid arthritis. Arthritis Rheumatol. 2016;68:1-26.

11. Smolen JS, Landewe R, Breedveld FC, et al. EULAR recommendations for the management of rheumatoid arthritis with synthetic and biological disease-modifying antirheumatic drugs: 2013 update. Ann Rheum Dis. 2014;73:492-509.

12. Weinblatt ME, Schiff M, Valente R, et al. Headto-head comparison of subcutaneous abatacept versus adalimumab for rheumatoid arthritis: findings of a phase IIIb, multinational, prospective, randomized study. Arthritis Rheum. 2013;65:28-38.

13. van Vollenhoven RF, Fleischmann R, Cohen S, et al. Tofacitinib or adalimumab versus placebo in rheumatoid arthritis. $\mathrm{N}$ Engl J Med. 2012;367:508-19.

14. Smolen JS, Burmester GR, Combe B, et al. Headto-head comparison of certolizumab pegol versus adalimumab in rheumatoid arthritis: 2-year efficacy and safety results from the randomised EXXELERATE study. Lancet. 2016;388:2763-74.

15. Nam JL, Ramiro S, Gaujoux-Viala C, et al. Efficacy of biological disease-modifying antirheumatic drugs: a systematic literature review informing the 2013 update of the EULAR recommendations for the management of rheumatoid arthritis. Ann Rheum Dis. 2014;73:516-28.

16. Nikiphorou E, Negoescu A, Fitzpatrick JD, et al. Indispensable or intolerable? Methotrexate in patients with rheumatoid and psoriatic arthritis: a retrospective review of discontinuation rates from a large UK cohort. Clin Rheumatol. 2014;33:609-14.

17. DiBenedetti DB, Zhou X, Reynolds M, Ogale S, Best $\mathrm{JH}$. Assessing methotrexate adherence in rheumatoid arthritis: a cross-sectional survey. Rheumatol Ther. 2015;2:73-84.

18. Soliman MM, Ashcroft DM, Watson KD, Lunt M, Symmons DP, Hyrich KL. Impact of concomitant use of DMARDs on the persistence with anti-TNF therapies in patients with rheumatoid arthritis: results from the British Society for Rheumatology Biologics Register. Ann Rheum Dis. 2011;70:583-9.

19. Burmester GR, Mariette X, Montecucco C, et al. Adalimumab alone and in combination with disease-modifying antirheumatic drugs for the treatment of rheumatoid arthritis in clinical practice: the Research in Active Rheumatoid Arthritis (ReAct) trial. Ann Rheum Dis. 2007;66:732-9.

20. Strand V, Kremer JM, Gruben D, Krishnaswami S, Zwillich SH, Wallenstein GV. Tofacitinib in combination with conventional disease-modifying antirheumatic drugs in patients with active rheumatoid arthritis: patient-reported outcomes from a phase III randomized controlled trial. Arthritis Care Res (Hoboken). 2017;69:592-8.

21. De Stefano R, Frati E, Nargi F, et al. Comparison of combination therapies in the treatment of rheumatoid arthritis: leflunomide-anti-TNF-alpha versus methotrexate-anti-TNF-alpha. Clin Rheumatol. 2010;29:517-24.

22. Narvaez J, Diaz-Torne C, Magallares B, et al. Comparative effectiveness of tocilizumab with either methotrexate or leflunomide in the treatment of rheumatoid arthritis. PLoS One. 2015;10:e123392.

23. Jones G, Sebba A, Gu J, et al. Comparison of tocilizumab monotherapy versus methotrexate 
monotherapy in patients with moderate to severe rheumatoid arthritis: the AMBITION study. Ann Rheum Dis. 2010;69:88-96.

24. Gabay C, Emery P, van Vollenhoven R, et al. Tocilizumab monotherapy versus adalimumab monotherapy for treatment of rheumatoid arthritis (ADACTA): a randomised, double-blind, controlled phase 4 trial. Lancet. 2013;381:1541-50.

25. Bykerk VP, Ostor AJ, Alvaro-Gracia J, et al. Comparison of tocilizumab as monotherapy or with add-on disease-modifying antirheumatic drugs in patients with rheumatoid arthritis and inadequate responses to previous treatments: an open-label study close to clinical practice. Clin Rheumatol. 2015;34:563-71.

26. Dougados M, Kissel K, Sheeran T, et al. Adding tocilizumab or switching to tocilizumab monotherapy in methotrexate inadequate responders: 24-week symptomatic and structural results of a 2-year randomised controlled strategy trial in rheumatoid arthritis (ACT-RAY). Ann Rheum Dis. 2013;72:43-50.

27. Dougados M, Kissel K, Conaghan PG, et al. Clinical, radiographic and immunogenic effects after 1 year of tocilizumab-based treatment strategies in rheumatoid arthritis: the ACT-RAY study. Ann Rheum Dis. 2014;73:803-9.

28. Burmester GR, Rigby WF, van Vollenhoven RF, et al. Tocilizumab combination therapy or monotherapy or methotrexate monotherapy in methotrexate-naive patients with early rheumatoid arthritis: 2-year clinical and radiographic results from the randomised, placebo-controlled FUNCTION trial. Ann Rheum Dis. 2017;76:1279-84.

29. Kaneko Y, Atsumi T, Tanaka Y, et al. Comparison of adding tocilizumab to methotrexate with switching to tocilizumab in patients with rheumatoid arthritis with inadequate response to methotrexate: 52 -week results from a prospective, randomised, controlled study (SURPRISE study). Ann Rheum Dis. 2016;75:1917-23.

30. Fleischmann R, Schiff M, Van der HD, et al. Baricitinib, methotrexate, or combination in patients with rheumatoid arthritis and no or limited prior disease-modifying antirheumatic drug treatment. Arthritis Rheumatol. 2017;69:506-17.

31. Fleischmann R, Mease PJ, Schwartzman S, et al. Efficacy of tofacitinib in patients with rheumatoid arthritis stratified by background methotrexate dose group. Clin Rheumatol. 2017;36:15-24.

32. Singh JA, Cameron C, Noorbaloochi S, et al. Risk of serious infection in biological treatment of patients with rheumatoid arthritis: a systematic review and meta-analysis. Lancet. 2015;386:258-65.

33. Strangfeld A, Eveslage M, Schneider M, et al. Treatment benefit or survival of the fittest: what drives the time-dependent decrease in serious infection rates under TNF inhibition and what does this imply for the individual patient? Ann Rheum Dis. 2011;70:1914-20.

34. RABBIT Risk Score of Infections. http://www. biologika-register.de/en/home/risk-score/. Accessed 23 June 2017.

35. Lahiri M, Dixon WG. Risk of infection with biologic antirheumatic therapies in patients with rheumatoid arthritis. Best Pract Res Clin Rheumatol. 2015;29:290-305.

36. Schiff M, Keiserman M, Codding C, et al. Efficacy and safety of abatacept or infliximab vs placebo in ATTEST: a phase III, multi-centre, randomised, double-blind, placebo-controlled study in patients with rheumatoid arthritis and an inadequate response to methotrexate. Ann Rheum Dis. 2008;67:1096-103.

37. Yun H, Xie F, Delzell E, et al. Risk of hospitalised infection in rheumatoid arthritis patients receiving biologics following a previous infection while on treatment with anti-TNF therapy. Ann Rheum Dis. 2015;74:1065-71.

38. Chung ES, Packer M, Lo KH, Fasanmade AA, Willerson JT. Randomized, double-blind, placebo-controlled, pilot trial of infliximab, a chimeric monoclonal antibody to tumor necrosis factor-alpha, in patients with moderate-to-severe heart failure: results of the anti-TNF Therapy Against Congestive Heart Failure (ATTACH) trial. Circulation. 2003;107:3133-40.

39. Mann DL, McMurray JJ, Packer M, et al. Targeted anticytokine therapy in patients with chronic heart failure: results of the Randomized Etanercept Worldwide Evaluation (RENEWAL). Circulation. 2004;109:1594-602.

40. Solomon DH, Rassen JA, Kuriya B, et al. Heart failure risk among patients with rheumatoid arthritis starting a TNF antagonist. Ann Rheum Dis. 2013;72:1813-8.

41. Kourbeti IS, Ziakas PD, Mylonakis E. Biologic therapies in rheumatoid arthritis and the risk of opportunistic infections: a meta-analysis. Clin Infect Dis. 2014;58:1649-57.

42. Plessner HL, Lin PL, Kohno T, et al. Neutralization of tumor necrosis factor (TNF) by antibody but not TNF receptor fusion molecule exacerbates chronic 
murine tuberculosis. J Infect Dis. 2007;195:1643-50.

43. Tubach F, Salmon D, Ravaud P, et al. Risk of tuberculosis is higher with anti-tumor necrosis factor monoclonal antibody therapy than with soluble tumor necrosis factor receptor therapy: the threeyear prospective French Research Axed on Tolerance of Biotherapies registry. Arthritis Rheum. 2009;60:1884-94.

44. Bigbee CL, Gonchoroff DG, Vratsanos G, Nadler SG, Haggerty HG, Flynn JL. Abatacept treatment does not exacerbate chronic Mycobacterium tuberculosis infection in mice. Arthritis Rheum. 2007;56:2557-65.

45. Winthrop KL, Park SH, Gul A, et al. Tuberculosis and other opportunistic infections in tofacitinib-treated patients with rheumatoid arthritis. Ann Rheum Dis. 2016;75:1133-8.

46. Campbell L, Chen C, Bhagat SS, Parker RA, Ostor AJ. Risk of adverse events including serious infections in rheumatoid arthritis patients treated with tocilizumab: a systematic literature review and meta-analysis of randomized controlled trials. Rheumatology (Oxford). 2011;50:552-62.

47. Hua C, Barnetche T, Combe B, Morel J. Effect of methotrexate, anti-tumor necrosis factor alpha, and rituximab on the immune response to influenza and pneumococcal vaccines in patients with rheumatoid arthritis: a systematic review and meta-analysis. Arthritis Care Res (Hoboken). 2014;66:1016-26.

48. Park JK, Lee MA, Lee EY, et al. Effect of methotrexate discontinuation on efficacy of seasonal influenza vaccination in patients with rheumatoid arthritis: a randomised clinical trial. Ann Rheum Dis. doi:10.1136/annrheumdis-2017-211128.

49. Winthrop KL, Silverfield J, Racewicz A, et al. The effect of tofacitinib on pneumococcal and influenza vaccine responses in rheumatoid arthritis. Ann Rheum Dis. 2016;75:687-95.

50. Mori S, Ueki Y, Akeda Y, et al. Pneumococcal polysaccharide vaccination in rheumatoid arthritis patients receiving tocilizumab therapy. Ann Rheum Dis. 2013;72:1362-6.

51. Strangfeld A, Richter A, Siegmund B, et al. Risk for lower intestinal perforations in patients with rheumatoid arthritis treated with tocilizumab in comparison to treatment with other biologic or conventional synthetic DMARDs. Ann Rheum Dis. 2017;76:504-10.

52. Mercer LK, Askling J, Raaschou P, et al. Risk of invasive melanoma in patients with rheumatoid arthritis treated with biologics: results from a collaborative project of 11 European biologic registers. Ann Rheum Dis. 2017;76:386-91.

53. Ramiro S, Gaujoux-Viala C, Nam JL, et al. Safety of synthetic and biological DMARDs: a systematic literature review informing the 2013 update of the EULAR recommendations for management of rheumatoid arthritis. Ann Rheum Dis. 2014;73:529-35.

54. Weinblatt M, Combe B, Covucci A, Aranda R, Becker JC, Keystone E. Safety of the selective costimulation modulator abatacept in rheumatoid arthritis patients receiving background biologic and nonbiologic disease-modifying antirheumatic drugs: a 1-year randomized, placebo-controlled study. Arthritis Rheum. 2006;54:2807-16.

55. Genovese MC, Cohen S, Moreland L, et al. Combination therapy with etanercept and anakinra in the treatment of patients with rheumatoid arthritis who have been treated unsuccessfully with methotrexate. Arthritis Rheum. 2004;50:1412-9.

56. Greenwald MW, Shergy WJ, Kaine JL, Sweetser MT, Gilder K, Linnik MD. Evaluation of the safety of rituximab in combination with a tumor necrosis factor inhibitor and methotrexate in patients with active rheumatoid arthritis: results from a randomized controlled trial. Arthritis Rheum. 2011;63:622-32.

57. Emery P, Gottenberg JE, Rubbert-Roth A, et al. Rituximab versus an alternative TNF inhibitor in patients with rheumatoid arthritis who failed to respond to a single previous TNF inhibitor: SWITCH-RA, a global, observational, comparative effectiveness study. Ann Rheum Dis. 2015;74:979-84.

58. Finckh A, Ciurea A, Brulhart L, et al. B cell depletion may be more effective than switching to an alternative anti-tumor necrosis factor agent in rheumatoid arthritis patients with inadequate response to anti-tumor necrosis factor agents. Arthritis Rheum. 2007;56:1417-23.

59. Bombardieri S, Ruiz AA, Fardellone P, et al. Effectiveness of adalimumab for rheumatoid arthritis in patients with a history of TNF-antagonist therapy in clinical practice. Rheumatology (Oxford). 2007;46:1191-9.

60. Remy A, Avouac J, Gossec L, Combe B. Clinical relevance of switching to a second tumour necrosis factor-alpha inhibitor after discontinuation of a first tumour necrosis factor-alpha inhibitor in rheumatoid arthritis: a systematic literature review and meta-analysis. Clin Exp Rheumatol. 2011;29:96-103. 
61. Smolen JS, Kay J, Doyle MK, et al. Golimumab in patients with active rheumatoid arthritis after treatment with tumour necrosis factor alpha inhibitors (GO-AFTER study): a multicentre, randomised, double-blind, placebo-controlled, phase III trial. Lancet. 2009;374:210-21.

62. Virkki LM, Valleala H, Takakubo Y, et al. Outcomes of switching anti-TNF drugs in rheumatoid arthritis-a study based on observational data from the Finnish Register of Biological Treatment (ROB-FIN). Clin Rheumatol. 2011;30:1447-54.

63. Schiff MH, von Kempis J, Goldblum R, Tesser JR, Mueller RB. Rheumatoid arthritis secondary non-responders to TNF can attain an efficacious and safe response by switching to certolizumab pegol: a phase IV, randomised, multicentre, double-blind, 12-week study, followed by a 12-week open-label phase. Ann Rheum Dis. 2014;73:2174-7.

64. Jani M, Barton A, Warren RB, Griffiths CE, Chinoy $\mathrm{H}$. The role of DMARDs in reducing the immunogenicity of TNF inhibitors in chronic inflammatory diseases. Rheumatology (Oxford). 2014;53:213-22.

65. Genovese MC, Becker JC, Schiff M, et al. Abatacept for rheumatoid arthritis refractory to tumor necrosis factor alpha inhibition. $\mathrm{N}$ Engl J Med. 2005;353:1114-23.

66. Cohen SB, Emery P, Greenwald MW, et al. Rituximab for rheumatoid arthritis refractory to anti-tumor necrosis factor therapy: results of a multicenter, randomized, double-blind, placebo-controlled, phase III trial evaluating primary efficacy and safety at twenty-four weeks. Arthritis Rheum. 2006;54:2793-806.

67. Emery P, Deodhar A, Rigby WF, et al. Efficacy and safety of different doses and retreatment of rituximab: a randomised, placebo-controlled trial in patients who are biological naive with active rheumatoid arthritis and an inadequate response to methotrexate (Study Evaluating Rituximab's Efficacy in MTX iNadequate rEsponders (SERENE)). Ann Rheum Dis. 2010;69:1629-35.

68. Mease PJ, Cohen S, Gaylis NB, et al. Efficacy and safety of retreatment in patients with rheumatoid arthritis with previous inadequate response to tumor necrosis factor inhibitors: results from the SUNRISE trial. J Rheumatol. 2010;37:917-27.

69. Bykerk VP, Ostor AJ, Alvaro-Gracia J, et al. Tocilizumab in patients with active rheumatoid arthritis and inadequate responses to DMARDs and/or TNF inhibitors: a large, open-label study close to clinical practice. Ann Rheum Dis. 2012;71:1950-4.

70. Emery P, Keystone E, Tony HP, et al. IL-6 receptor inhibition with tocilizumab improves treatment outcomes in patients with rheumatoid arthritis refractory to anti-tumour necrosis factor biologicals: results from a 24-week multicentre randomised placebo-controlled trial. Ann Rheum Dis. 2008;67:1516-23.

71. Burmester GR, Blanco R, Charles-Schoeman C, et al. Tofacitinib (CP-690,550) in combination with methotrexate in patients with active rheumatoid arthritis with an inadequate response to tumour necrosis factor inhibitors: a randomised phase 3 trial. Lancet. 2013;381:451-60.

72. Genovese MC, Kremer J, Zamani O, et al. Baricitinib in patients with refractory rheumatoid arthritis. N Engl J Med. 2016;374:1243-52.

73. Salliot C, Dougados M, Gossec L. Risk of serious infections during rituximab, abatacept and anakinra treatments for rheumatoid arthritis: meta-analyses of randomised placebo-controlled trials. Ann Rheum Dis. 2009;68:25-32.

74. Xanthouli P, Sailer S, Fiehn C. Rituximab (RTX) as an alternative to TNF-alpha antagonists in patients with rheumatoid arthritis and high risk of severe infections: a systematic analysis of the experience in one center. Open Rheumatol J. 2012;6:286-9.

75. van Vollenhoven RF, Emery P, Bingham CO III, et al. Long-term safety of rituximab in rheumatoid arthritis: 9.5-year follow-up of the global clinical trial programme with a focus on adverse events of interest in RA patients. Ann Rheum Dis. 2013;72:1496-502.

76. Taylor PC, Keystone EC, Van der HD, et al. Baricitinib versus placebo or adalimumab in rheumatoid arthritis. N Engl J Med. 2017;376:652-62.

77. Tarp S, Eric FD, Boers M, et al. Risk of serious adverse effects of biological and targeted drugs in patients with rheumatoid arthritis: a systematic review meta-analysis. Rheumatology (Oxford). 2017;56:417-25.

78. Schiff M, Pritchard C, Huffstutter JE, et al. The 6month safety and efficacy of abatacept in patients with rheumatoid arthritis who underwent a washout after anti-tumour necrosis factor therapy or were directly switched to abatacept: the ARRIVE trial. Ann Rheum Dis. 2009;68:1708-14.

79. Burmester GR, Rubbert-Roth A, Cantagrel A, et al. Efficacy and safety of subcutaneous tocilizumab versus intravenous tocilizumab in combination with traditional DMARDs in patients with RA at week 97 (SUMMACTA). Ann Rheum Dis. 2016;75:68-74.

80. Mueller RB, Gengenbacher M, Richter S, Dudler J, Moller B, von Kempis J. Change from subcutaneous 
to intravenous abatacept and back in patients with rheumatoid arthritis as simulation of a vacation: a prospective phase IV, open-label trial (A-BREAK). Arthritis Res Ther. 2016;18:88.

81. Hiley J, Homer D, Clifford C. Patient self-injection of methotrexate for inflammatory arthritis: a study evaluating the introduction of a new type of syringe and exploring patients' sense of empowerment. Musculoskelet Care. 2008;6:15-30.

82. Fleischmann R, van Adelsberg J, Lin Y, et al. Sarilumab and nonbiologic disease-modifying antirheumatic drugs in patients with active rheumatoid arthritis and inadequate response or intolerance to tumor necrosis factor inhibitors. Arthritis Rheumatol. 2017;69:277-90.

83. Genovese MC, Fleischmann R, Kivitz AJ, et al. Sarilumab plus methotrexate in patients with active rheumatoid arthritis and inadequate response to methotrexate: results of a phase III study. Arthritis Rheumatol. 2015;67:1424-37.

84. Burmester GR, Lin Y, Patel R, et al. Efficacy and safety of sarilumab monotherapy versus adalimumab monotherapy for the treatment of patients with active rheumatoid arthritis (MONARCH): a randomised, double-blind, parallel-group phase III trial. Ann Rheum Dis. 2017;76:840-7.

85. Smolen JS, Agarwal SK, Ilivanova E, et al. A randomised phase II study evaluating the efficacy and safety of subcutaneously administered ustekinumab and guselkumab in patients with active rheumatoid arthritis despite treatment with methotrexate. Ann Rheum Dis. 2017;76:831-9.

86. Genovese MC, Durez P, Richards HB, et al. One-year efficacy and safety results of secukinumab in patients with rheumatoid arthritis: phase II, dose-finding, double-blind, randomized, placebo-controlled study. J Rheumatol. 2014;41:414-21.

87. Martin DA, Churchill M, Flores-Suarez L, et al. A phase Ib multiple ascending dose study evaluating safety, pharmacokinetics, and early clinical response of brodalumab, a human anti-IL-17R antibody, in methotrexate-resistant rheumatoid arthritis. Arthritis Res Ther. 2013;15:R164.

88. Genovese MC, Greenwald M, Cho CS, et al. A phase II randomized study of subcutaneous ixekizumab, an anti-interleukin-17 monoclonal antibody, in rheumatoid arthritis patients who were naive to biologic agents or had an inadequate response to tumor necrosis factor inhibitors. Arthritis Rheumatol. $2014 ; 66: 1693-704$.

89. Generics and Biosimilars Initiative Online. Biosimilars approved in Europe. 2017. http://www.
gabionline.net/Biosimilars/General/Biosimilarsapproved-in-Europe. Accessed 23 June 2017.

90. Barber J. FDA advisory panel backs Amgen's proposed biosimilar of AbbVie's Humira. 2016. http:// www.firstwordpharma.com/node/1399106\#axzz4EO 2ytw2T. Accessed 23 June 2017.

91. Smolen JS, Nash P, Durez P, et al. Maintenance, reduction, or withdrawal of etanercept after treatment with etanercept and methotrexate in patients with moderate rheumatoid arthritis (PRESERVE): a randomised controlled trial. Lancet. 2013;381:918-29.

92. van Herwaarden N, Van der MA, Minten MJ, et al. Disease activity guided dose reduction and withdrawal of adalimumab or etanercept compared with usual care in rheumatoid arthritis: open label, randomised controlled, non-inferiority trial. BMJ. 2015;350:h1389.

93. Huizinga TW, Conaghan PG, Martin-Mola E, et al. Clinical and radiographic outcomes at 2 years and the effect of tocilizumab discontinuation following sustained remission in the second and third year of the ACT-RAY study. Ann Rheum Dis. $2015 ; 74: 35-43$.

94. Smolen JS, Emery P, Ferraccioli GF, et al. Certolizumab pegol in rheumatoid arthritis patients with low to moderate activity: the CERTAIN double-blind, randomised, placebo-controlled trial. Ann Rheum Dis. 2015;74:843-50.

95. Gremese E, Salaffi F, Bosello SL, et al. Very early rheumatoid arthritis as a predictor of remission: a multicentre real life prospective study. Ann Rheum Dis. 2013;72:858-62.

96. Allaart CF, Goekoop-Ruiterman YP, Vries-Bouwstra JK, Breedveld FC, Dijkmans BA. Aiming at low disease activity in rheumatoid arthritis with initial combination therapy or initial monotherapy strategies: the BeSt study. Clin Exp Rheumatol. 2006;24:S-82.

97. Weinblatt ME, Keystone EC, Furst DE, et al. Adalimumab, a fully human anti-tumor necrosis factor alpha monoclonal antibody, for the treatment of rheumatoid arthritis in patients taking concomitant methotrexate: the ARMADA trial. Arthritis Rheum. 2003;48:35-45.

98. Keystone EC, Kavanaugh AF, Sharp JT, et al. Radiographic, clinical, and functional outcomes of treatment with adalimumab (a human anti-tumor necrosis factor monoclonal antibody) in patients with active rheumatoid arthritis receiving concomitant methotrexate therapy: a randomized, placebo-controlled, 52-week trial. Arthritis Rheum. 2004;50:1400-11. 
99. Keystone E, Heijde D, Mason D Jr, et al. Certolizumab pegol plus methotrexate is significantly more effective than placebo plus methotrexate in active rheumatoid arthritis: findings of a 52 week, phase III, multicenter, randomized, double-blind, placebo-controlled, parallel-group study. Arthritis Rheum. 2008;58:3319-29.

100. Smolen J, Landewe RB, Mease P, et al. Efficacy and safety of certolizumab pegol plus methotrexate in active rheumatoid arthritis: the RAPID 2 study. A randomised controlled trial. Ann Rheum Dis. 2009;68:797-804.

101. Moreland LW, Schiff MH, Baumgartner SW, et al. Etanercept therapy in rheumatoid arthritis. A randomized, controlled trial. Ann Intern Med. 1999;130:478-86.

102. Kay J, Matteson EL, Dasgupta B, et al. Golimumab in patients with active rheumatoid arthritis despite treatment with methotrexate: a randomized, double-blind, placebo-controlled, dose-ranging study. Arthritis Rheum. 2008;58:964-75.

103. Keystone EC, Genovese MC, Klareskog L, et al. Golimumab, a human antibody to tumour necrosis factor alpha given by monthly subcutaneous injections, in active rheumatoid arthritis despite methotrexate therapy: the GO-FORWARD study. Ann Rheum Dis. 2009;68:789-96.

104. Maini R, St Clair EW, Breedveld F, et al. Infliximab (chimeric anti-tumour necrosis factor alpha monoclonal antibody) versus placebo in rheumatoid arthritis patients receiving concomitant methotrexate: a randomised phase III trial. ATTRACT Study Group. Lancet. 1999;354:1932-9.

105. Abe T, Takeuchi T, Miyasaka N, et al. A multicenter, double-blind, randomized, placebo controlled trial of infliximab combined with low dose methotrexate in Japanese patients with rheumatoid arthritis. J Rheumatol. 2006;33:37-44.

106. Kremer JM, Genant HK, Moreland LW, et al. Effects of abatacept in patients with methotrexate-resistant active rheumatoid arthritis: a randomized trial. Ann Intern Med. 2006;144:865-76.

107. Kremer JM, Dougados M, Emery P, et al. Treatment of rheumatoid arthritis with the selective costimulation modulator abatacept: twelve-month results of a phase IIb, double-blind, randomized, placebo-controlled trial. Arthritis Rheum. 2005;52:2263-71.

108. Edwards JC, Szczepanski L, Szechinski J, et al. Efficacy of B-cell-targeted therapy with rituximab in patients with rheumatoid arthritis. N Engl J Med. 2004;350:2572-81.

109. Emery P, Fleischmann R, Filipowicz-Sosnowska A, et al. The efficacy and safety of rituximab in patients with active rheumatoid arthritis despite methotrexate treatment: results of a phase IIB randomized, double-blind, placebo-controlled, dose-ranging trial. Arthritis Rheum. 2006;54:1390-400.

110. Smolen JS, Beaulieu A, Rubbert-Roth A, et al. Effect of interleukin-6 receptor inhibition with tocilizumab in patients with rheumatoid arthritis (OPTION study): a double-blind, placebo-controlled, randomised trial. Lancet. 2008;371:987-97.

111. Maini RN, Taylor PC, Szechinski J, et al. Double-blind randomized controlled clinical trial of the interleukin-6 receptor antagonist, tocilizumab, in European patients with rheumatoid arthritis who had an incomplete response to methotrexate. Arthritis Rheum. 2006;54:2817-29.

112. van der Heijde, Tanaka Y, Fleischmann R, et al. Tofacitinib (CP-690,550) in patients with rheumatoid arthritis receiving methotrexate: twelve-month data from a twenty-four-month phase III randomized radiographic study. Arthritis Rheum. 2013;65:559-570.

113. Keystone EC, Taylor PC, Drescher E, et al. Safety and efficacy of baricitinib at 24 weeks in patients with rheumatoid arthritis who have had an inadequate response to methotrexate. Ann Rheum Dis. 2015;74:333-40. 